\title{
EVALUASI KEMAMPUAN LAHAN MARGINAL DESA SIHIONG BONATUA LUNASI TOBASA UNTUK TANAMAN ANGGUR (Vitis vinifera L.) DAN JAMBU BIJI (Psidium guajava L.)
}

\author{
Bintang*, Supriadi, Mariani Sembiring
}

Program Studi Agroekoteknologi Fakultas Pertanian, USU, Medan- 20155

Corresponding author : bintangsitorus@ymail.com

\begin{abstract}
ABSTRAK
Penelitian bertujuan untuk mengetahui kemampuan lahan marjinal di Desa Sihiong Kecamatan Bonatua Lunasi Kabupaten Tobasa mendukung tanaman anggur (Vitis vinifera L.) dan jambu biji (Psidium guajava L.), dimulai tahun 2012-2014 menggunakan metoda survey, dengan dua tahapan yakni mengklasifikasikan kemampuan lahan di Sihiong dan mengevaluasi kesesuaian lahan terhadap tanaman anggur dan jambu biji. Data primer dari lapangan adalah kemiringan lereng, erosi, solum, drainase, singkapan batuan dan bahaya banjir/genangan. Analisis properti tanah (tekstur, permeabiltas, bulk density, salinitas, bahan organik, pH, Kapasitas Tukar Kation, Kejenuhan Basa) dilakukan di laboratorium Riset dan Teknologi Fakultas Pertanian USU Medan. Hasil penelitian menunjukkan bahwa lahan daerah Sihiong termasuk kelas III dengan kemampuan lahan aktual kelas III(es). Upaya perbaikan dapat dilakukan untuk mengatasi erosi dengan membuat teras di lahan sedangkan tekstur tanah Lempung Berpasir (t4) tidak dapat dirubah. Dengan adanya perbaikan maka kemampuan lahan potensial Sihiong menjadi kelas III(s). Kemampuan lahan di Desa Sihiong dapat mendukung tanaman Tanaman Anggur (Vitis vinifera L.) pada kesesuaian lahan aktual terendah S3 (eh) dan upaya perbaikan akan meningkatkan kelas potensial menjadi $S 2$ (tc,wa) dengan faktor pembatas tc,wa (temperatur dan ketersediaan air/lama masa kering) tidakdapat/sulit diperbaiki. Kesesuaian untuk tanaman jambu biji (Psidium guajava L.) berada pada kelas $S 3$ (nr,eh) dengan faktor pembatas retensi hara dan bahaya erosi. Alternatif perbaikan dengan pemberian bahan organik yang diperkaya mineral basa dapat meningkatkan kelas kesesuaian lahan potensial menjadi S2 (tc) dengan faktor pembatas tc (temperatur) yang sulit diperbaiki.
\end{abstract}

Kata kunci: Lahan marginal, Tobasa, anggur, jambu biji,

\section{PENDAHULUAN}

Kemampuan lahan adalah potensi lahan untuk penggunaan berbagai sistem pertanian secara umum tanpa menjelaskan peruntukan untuk jenis tanaman tertentu maupun tindakan - tindakan pengelolaannya. Tujuannya adalah untuk mengelompokkan lahan yang dapat diusahakan bagi pertanian berdasarkan potensi dan pembatasnya agar dapat berproduksi secara berkesinambungan. Kemampuan lahan merupakan lingkungan fisik yang meliputi iklim, relief, tanah, hidrologi, dan vegetasi. Faktor-faktor ini hingga batas tertentu mempengaruhi potensi dan kemampuan lahan untuk mendukung suatu tipe penggunaan tertentu (Arsyad, 1989).

Lahan marginal dapat dilihat dari ciri tanah dengan kondisi seperti penurunan status hara dan dan aktifitas biologi tanah serta kandungan bahan organik. Lahan dengan kapasitas menahan air yang sangat rendah, lahan yang mengalami kerusakan dan kehilangan fungsi hidrologis maupun 
ekonomi yang diakibatkan oleh erosi air atau angin atau telah terjadi salinitas dan pencemaran yang hebat (Suharta, 2010).

Desa Sihiong merupakan salah satu desa di Kecamatan Bonatua Lunasi Kabupaten Toba Samosir, berjarak sekitar 20 kilometer dari Daerah Tujuan Wisata (DTW) Parapat. Mata pencarian utama masyarakat adalah bertani padi sawah. Lahan kering diusahakan untuk beragam penggunaan, seperti tanaman pangan (padi, jagung, ubi) dan hortikultura (bawang prei, sawi, cabai, papaya dan pisang). Sebagian masyarakat ada yang mengusahakan tanaman tahunan seperti coklat dan kopi (BPS, 2010). Sebagai daerah yang bertetangga dengan DTW perlu dikaji kemampuan lahannya untuk introduksi tanaman hortikultura yang diharapkan dapat meningkatkan pendapatan masyarakat seperti anggur (Vitis vinifera L.) dan jambu biji (Psidium guajava L.).

Kemampuan lahan dikelompokan kedalam kelas menggunakan huruf Romawi (I sampai dengan VIII). Lahan kelas I adalah lahan ideal untuk pertanian dengan faktor penghambat terkecil/ minimum. Selain lahan kelas I, untuk kelas lain membutuhkan upaya untuk mengatasi faktor penghambat yang aktual untuk pertanian. Tanah pada kelas I sampai IV adalah tanah atau lahan yang sesuai digunakan untuk tanaman pertanian pada umumnya (tanaman semusim atau tahunan), maupun untuk rumput makanan ternak, padang rumput dan hutan. Tanah pada kelas V, VI dan VII tidak sesuai untuk pertanian, melainkan sesuai untuk padang rumput, tanaman pohon-pohon atau vegetasi alami. Tanah dalam kelas VIII harus dibiarkan dalam keadaan alami. Dengan demikian, semakin tinggi kelasnya (semakin besar angka kelas) semakin rendah kualitas lahannya (Rayes, 2007).

\section{BAHAN DAN METODE}

Lokasi penelitian berada di desa Sihiong pada koordinat $99^{0} 02^{\prime}$ BT- $99^{0}$ 15' BT dan $\quad 2^{0} 29^{\prime} \mathrm{LU}-2^{0} 39^{\prime} \mathrm{LU}$ dengan ketinggian 974 meter di atas permukaan laut, dimulai tahun 2012 hingga 2014. Penelitian menggunakan metoda survey dengan dua tahapan yakni mengklasifikasikan kemampuan lahan dan dilanjutkan dengan evaluasi kesesuaian lahan untuk tanaman Anggur (Vitis vinifera L.) dan Jambu Biji (Psidium guajava L.).

Data lapangan meliputi temperature rata-rata tahunan, curahan hujan tahunan, drainase tanah, kedalaman efektif (solum), kemiringan lereng, batuan permukaan dan singkapan dan bahaya erosi. Properti tanah meliputi tekstur, permeabiltas, bulk density, salinitas, bahan organik, pH, Kapasitas Tukar Kation dan Kejenuhan Basa dianalisa di laboratorium Riset dan Teknologi Fakultas Pertanian USU Medan. Untuk analisa laboratorium digunakan contoh tanah komposit dari lapangan.

\section{HASIL DAN PEMBAHASAN}

Hasil pengamatan menunjukkan kelas kemampuan lahan aktual pada desa Sihiong termasuk kedalam kelas III(e,s) dengan faktor penghambat kelerengan dan tekstur. Lahan kelas III memiliki hambatan dan memerlukan tindakan konservasi yang khusus seperti menanam tanaman semusim dan/atau pembuatan teras. Di lokasi hambatan lereng dapat diatasi dengan pembuatan teras namun tekstur tanah Lempung Berpasir (t4) tidak dapat dirubah, maka lahan di Desa Sihiong dimasukkan pada Kelas Kemampuan Lahan Potensial III(s). Lahan Desa Sihiong termasuk lahan marginal karena faktor penghambat kelerengan dan tekstur tanah yang didominasi oleh pasir. 
Tabel 1. Hasil Analisis Lapangan dan Laboratorium untuk tanah di Desa Sihiong Kecamatan Bonatua Lunasi Kabupaten Tobasa

\begin{tabular}{|c|c|c|c|}
\hline $\begin{array}{l}\mathbf{N} \\
\mathbf{0}\end{array}$ & Parameter & Data & Klasifikasi \\
\hline 1 & $\begin{array}{l}\text { Kemiringan } \\
\text { Lereng }\end{array}$ & $12,3 \%$ & Bergelombang (C) \\
\hline 2 & Erodibilitas & 0,18 & Rendah (K2) \\
\hline 3 & Kerusakan Erosi & $0,43 \%$ & Ringan (e1) \\
\hline 4 & Kedalaman Tanah & $>90 \mathrm{~cm}$ & Dalam (k0) \\
\hline 5 & Tekstur Tanah & $\begin{array}{l}\text { Pasir } 68 \% \\
\text { Debu } 12 \% \\
\text { Liat } 20 \%\end{array}$ & $\underset{(\mathrm{t} 4)}{\text { Lempung Berpasir }}$ \\
\hline 6 & Permeabilitas & $0,506 \mathrm{~cm} / \mathrm{jam}$ & Agak Lambat (P1) \\
\hline 7 & Drainase Tanah & $\begin{array}{l}\text { Tidak terdapat karatan, } \\
>150 \mathrm{~cm} \text { Profil tanah tera- } \\
\text { ng seragam, aerasi baik }\end{array}$ & $\mathrm{d} 1$ \\
\hline 8 & Batuan Tanah & $\begin{array}{c}\text { diameter }>2 \mathrm{~mm}-7,5 \mathrm{~mm}:<15 \% \text { Vol tanah } \\
\text { diameter }>25 \mathrm{~cm}:<0,01 \text { permukaan tertutup } \\
\text { batuan tersingkap: }<2 \% \text { permukaan } \\
\text { tertutup }\end{array}$ & Sedikit (b0) \\
\hline 9 & Bahaya Banjir & $\begin{array}{l}\text { dalam periode } 1 \text { tahun tanah tidak pernah } \\
\text { kebanjiran selama }>24 \text { jam }\end{array}$ & Tidak Pernah $(\mathrm{O} 0)$ \\
\hline 10 & Salinitas Tanah & $4,0 \mathrm{mmhos} / \mathrm{cm}$ & bebas (G0) \\
\hline
\end{tabular}

Hasil pengamatan menunjukkan kelas kemampuan lahan aktual pada desa Sihiong termasuk kedalam kelas III(e,s) dengan faktor penghambat kelerengan dan tekstur. Lahan kelas III memiliki hambatan dan memerlukan tindakan konservasi yang khusus seperti menanam tanaman semusim dan/atau pembuatan teras. Di lokasi hambatan lereng dapat diatasi dengan pembuatan teras namun tekstur tanah Lempung Berpasir (t4) tidak dapat dirubah, maka lahan di Desa Sihiong dimasukkan pada Kelas Kemampuan Lahan Potensial III(s). Lahan Desa Sihiong termasuk lahan marginal karena faktor penghambat kelerengan dan tekstur tanah yang didominasi oleh pasir.

Data karakteristik tanah Desa Sihiong dievaluasi untuk kemungkingan introduksi jenis tanaman yang direncanakan dapat sesuai dan berkembang. Tanaman yang dipilih adalah anggur (Vitis vinifera L.) dan jambu biji (Psidium guajava L.)
Evaluasi pencocokan karakteristik tanah Sihiong untuk tanaman Anggur menghasilkan kelas kesesuaian lahan aktual terendah S3 (eh) dengan faktor pembatas bahaya erosi sub kelas kemiringan lereng dan kelas S3 (nr) dengan faktor pembatas retensi hara sub kelas $\mathrm{pH}$.

Upaya perbaikan dapat dilakukan untuk mengatasi lereng dengan membuat teras dan penggunaan bahan organik serta bahan pembenah kemasaman tanah seperti kapur. Dengan upaya ini maka kesesuaian potensialnya meningkat menjadi kelas $\mathbf{S 2}$ (tc,wa). Faktor pembatas tc,wa (temperatur dan ketersediaan air/lama masa kering) hampir tidak dapat diperbaiki.

Berdasarkan hasil pencocokan karakteristik tanah untuk tanaman jambu biji maka diperoleh kelas kesesuaian lahan S3 (nr,eh) dengan faktor pembatas retensi hara sub kelas kejenuhan basa dan bahaya erosi sub kelas kemiringan lereng. 
Upaya perbaikan yang dapat dilakukan adalah usaha pengelolaan lereng dengan teras dan perbaikan retensi hara dengan meningkatkan kejenuhan basa melalui bahan organik yang diperkaya dengan mineral basa maka kelas kesesuaian lahan potensial meningkat menjadi $\quad$ S2 (tc). Faktor pembatas tc (temperatur) hampir tidak dapat diperbaiki.

\section{SIMPULAN}

Lahan di Desa Sihiong termasuk lahan marginal Kelas Kemampuan Lahan III $(e, s)$ dengan faktor penghambat kelerengan dan tekstur. Kemampuan Lahan di Desa Sihiong dapat mendukung tanaman Tanaman Anggur (Vitis vinifera L.) pada kesesuaian lahan aktual terendah S3 (eh) dan upaya perbaikan akan meningkatkan kelas potensial menjadi S2 (tc,wa) dengan faktor pembatas tc,wa (temperatur dan ketersediaan air/lama masa kering) yang tidak/sulit dapat diperbaiki

Tanaman jambu biji berada pada kelas kesesuaian lahan S3 (nr,eh) dengan faktor pembatas retensi hara dan bahaya erosi. Alternatif perbaikan dengan pemberian bahan organik yang diperkaya mineral basa dapat meningkatkan kelas kesesuaian lahan potensial menjadi S2 (tc) dengan faktor pembatas tc (temperatur) yang sulit diperbaiki.

\section{DAFTAR PUSTAKA}

Abdullah, T. S. 1996. Survai Tanah dan Evalusi Lahan. Penerbit Swadaya. Jakarta.

Arsyad, S. 1989. Konservasi Tanah dan Air. Penerbit IPB. Bogor

BPS, 2010. Tobasa dalam Angka Badan Pusat Statistik Kabupaten Toba Samosir.

Djaenuddin, D., Marwan., Subagjo., dan A. Hidayat. 2013. Petunjuk Teknis Evaluasi Lahan untuk Komoditas Pertanian. Balai Penelitian Tanah, Puslitbangtanak, Bogor. 154 p.

Paiman, A. dan Y.G. Armandu. 2010. Potensi Fisik dan Kimia Lahan Margianal untuk Pengembangan Pengusahaan Tanaman Melinjo dan Karet di Provinsi Jambi Jurnal Akta Agrosia 13 (1) : 89-97.

Rayes, M.L., 2007. Metode Inventarisasi Sumber Daya Lahan. Penerbit Andi Offset. Yogyakarta

Suharta, N. 2010. Karakteristik dan Permasalahan Tanah Marginal dari Batuan Sedimen Masam di Kalimantan. Jurnal Litbang Pertanian. Bogor.

Suprapto. 2000. Berbagai Masukan Teknologi Untuk Meningkatkan Produktivitas Lahan Marginal. Laporan Akhir Penelitian SUT Diversifikasi Lahan Margianl di Kematan Gerokgak. Buleleng.

Yuwono, N. W. 2009. Membangun Kesuburan Tanah di Lahan Marginal. Jurnal Ilmu Tanah dan Lingkungan. Fakultas Pertanian UGM. 


\section{Lampiran:}
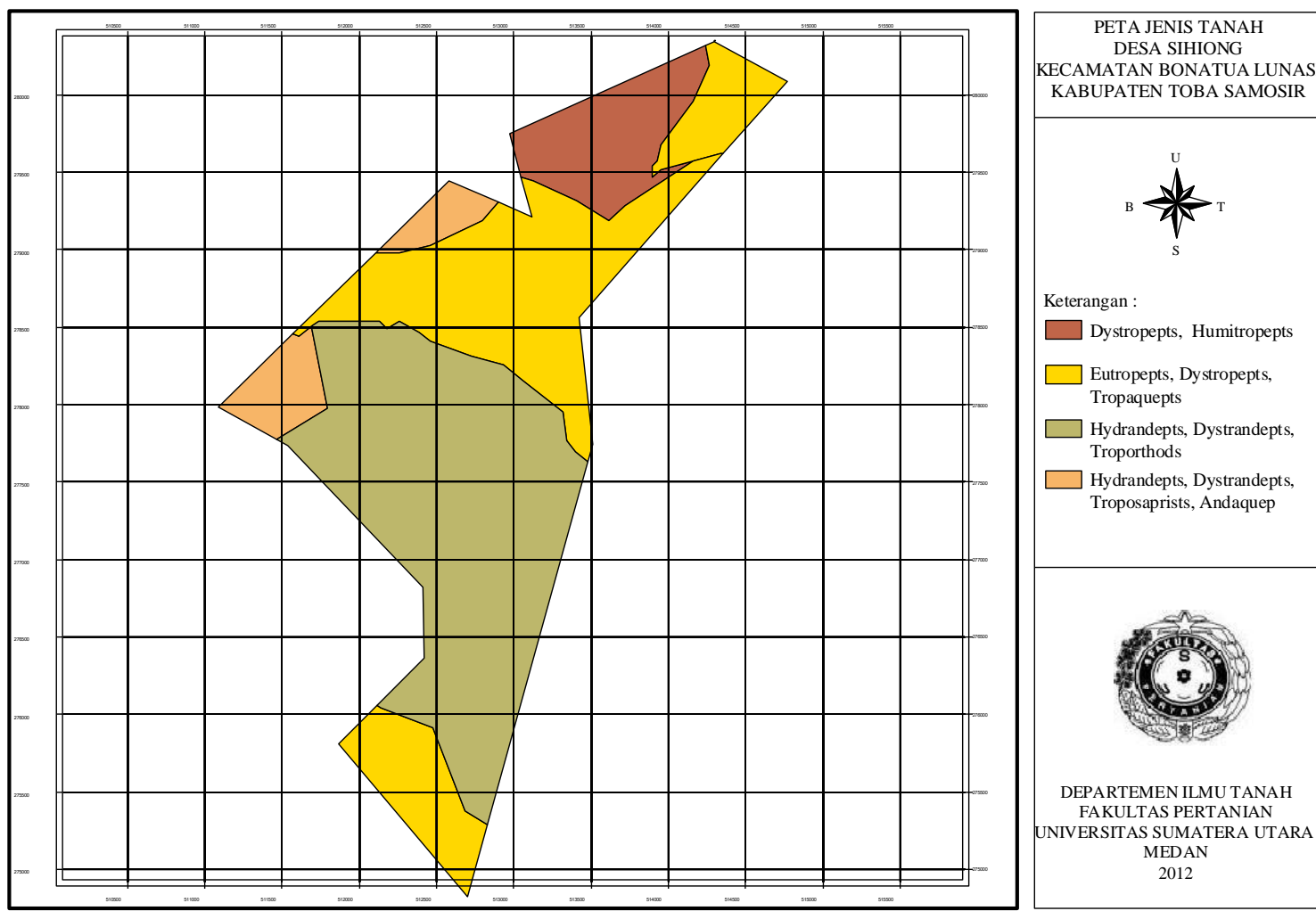

Gambar 1. Peta jenis Tanah Desa Sihiong Kec.

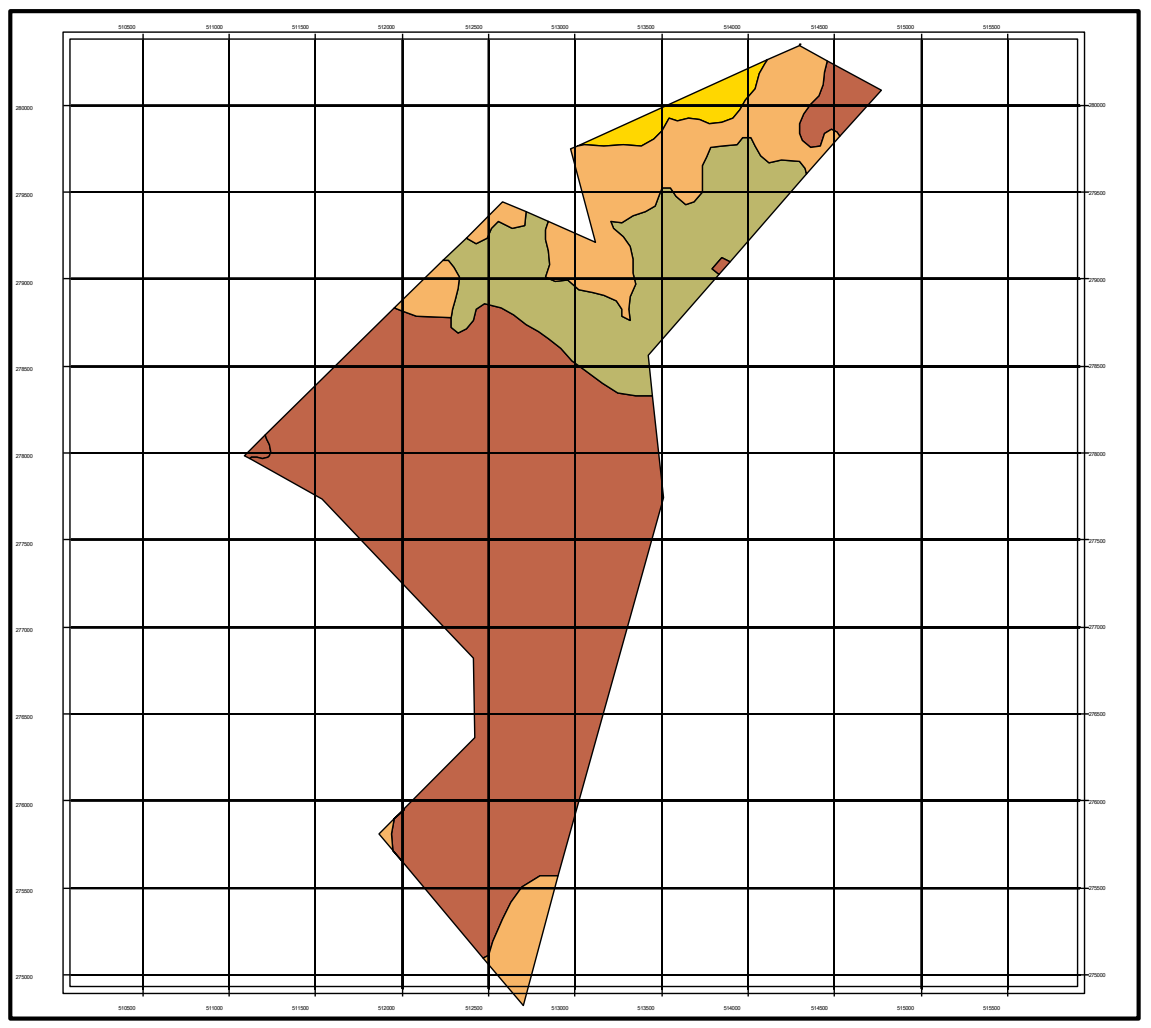

PETA KEMIRINGAN LERENG DESA SIHIONG

KECAMATAN BONATUA LUNAS KABUPATEN TOBA SAMOSIR

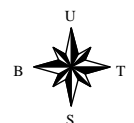

Keterangan :

Bergelombang (8-15\% Curam $(45-65 \%)$

$\square$ Datar (0-3\%)

$\square$ Landai (3-8\%)

Gambar 2. Peta Kemiringan Lereng Desa Sihiong Kec. Bonatua Lunasi Kab. Tobasa 

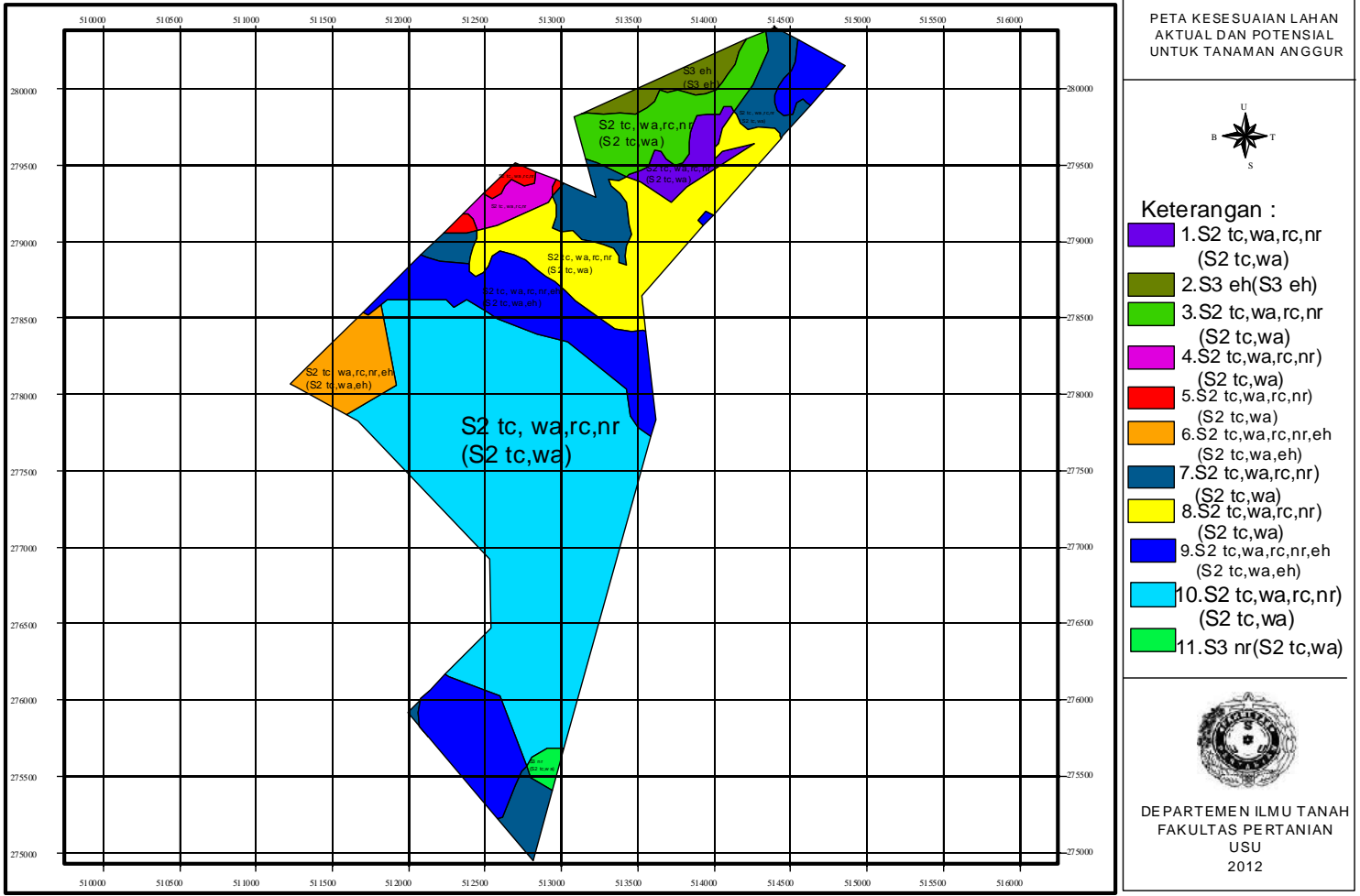

Gambar 3. Kelas Kesesuaian Lahan untuk Tanaman Anggur (Vitis vinifera L.)

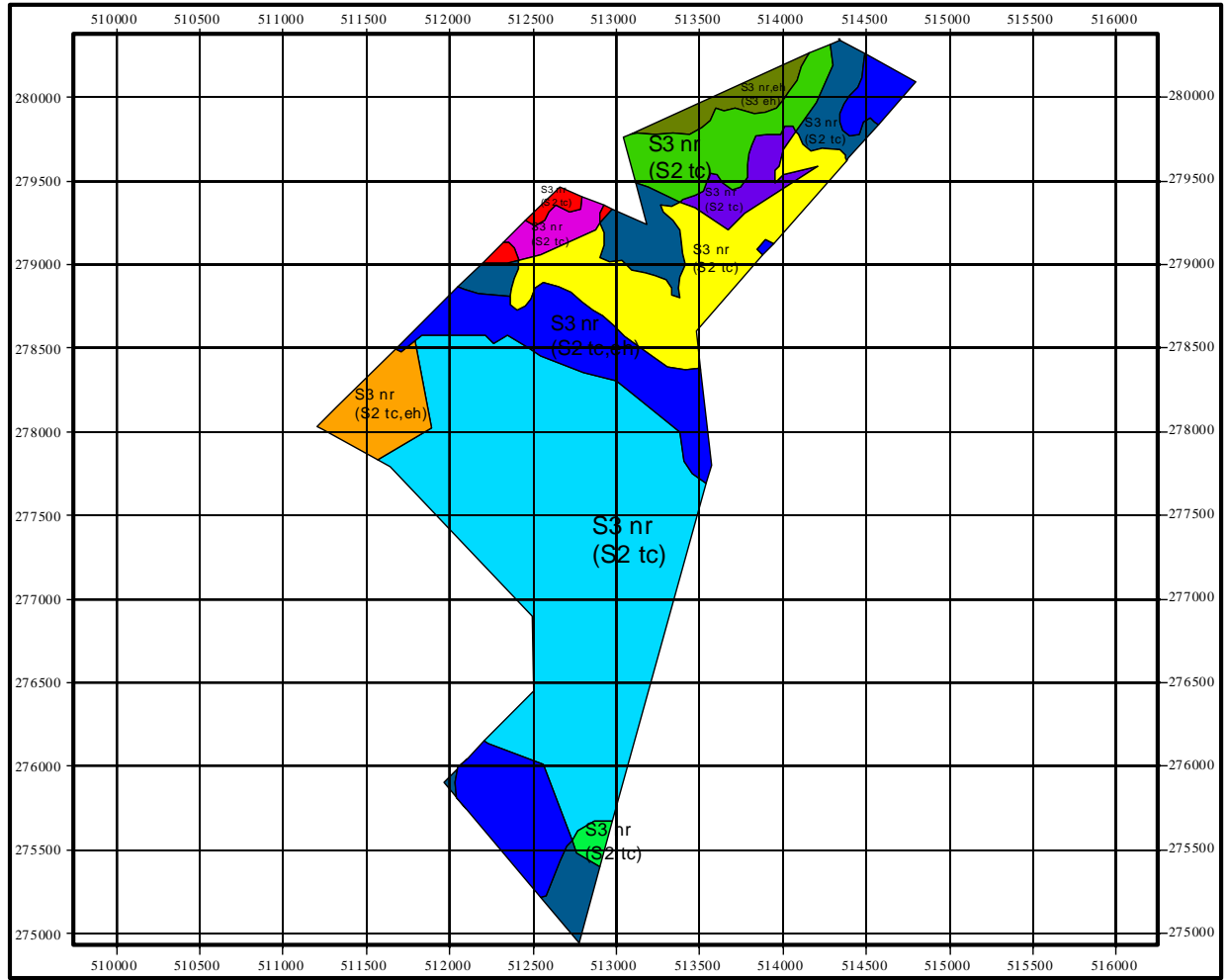

PETA KESESUAIAN LAHAN AKTUAL DAN POTENSIAL

柴

Keterangan :

1.S3 $\mathrm{nr}(\mathrm{S} 2 \mathrm{tc})$ 2.S3 $\mathrm{nr}, \mathrm{eh}(\mathrm{S} 3 \mathrm{eh}$

$3 . \mathrm{S} 3 \mathrm{nr}(\mathrm{S} 2 \mathrm{tc})$

4.S3 $\mathrm{nr}(\mathrm{S} 2 \mathrm{tc})$

5.S3 $\mathrm{nr}(\mathrm{S} 2 \mathrm{tc})$

6.S3 $\mathrm{nr}$ (S2 tc,eh) 7.S3 $\mathrm{nr}(\mathrm{S} 2 \mathrm{tc})$

8.S3 $\mathrm{nr}(\mathrm{S} 2 \mathrm{tc})$

9.S3 $\mathrm{nr}(\mathrm{S} 2 \mathrm{tc}, \mathrm{eh})$

10.S3 $\mathrm{nr}(\mathrm{S} 2 \mathrm{tc})$

11.S3 $\mathrm{nr}(\mathrm{S} 2 \mathrm{tc})$

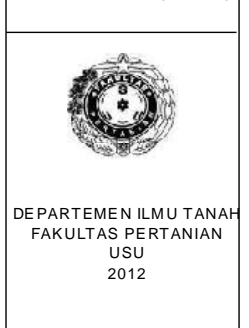

Gambar 4. Kelas Kesesuaian Lahan untuk Tanaman Jambu Biji (Psidium guajava L.) 